\title{
Proposta de modelo descritivo-normativo de subsistemas de interação e navegação de revistas digitais multimídia para tablets
}

\author{
Proposal for a descriptive-normative model of \\ interaction subsystems and navigation subsystems \\ of multimedia digital magazines for tablets
}

\author{
Sergio R. Gurski, Stephania Padovani, Maicon B. Puppi
}

revista digital

multimídia,

navegação em

revistas digitais,

interação em

revistas digitais

digital multimedia

magazine,

digital magazine

navigation,

digital magazine

interaction

\begin{abstract}
O presente estudo apresenta a proposta de um modelo descritivo-normativo para a caracterização e a avaliação de subsistemas de interação e navegação de revistas digitais multimídia. Intenta-se que o modelo proposto possa ser utilizado como recurso na fase de análise de similares no design de revistas multimídia, ou como recurso de avaliação para o redesign de uma revista multimídia já existente. Apresenta o processo de desenvolvimento do modelo, sua estrutura de enquadramento de parâmetros e seus elementos componentes. Demonstra sua aplicação a partir da caracterização e avaliação de duas revistas multimídia, bem como os resultados desta análise. Conclui demonstrando que a proposta de modelo descritivo-normativo se adequa aos objetivos do estudo e apresenta desdobramentos futuros.
\end{abstract}

This paper presents a proposal for a descriptive-normative model for the characterization and evaluation of interaction subsystem and navigation subsystem of multimedia digital magazines. The intention is that the proposed model can be used as a resource in the competitor analysis phase in multimedia magazines design or as a resource of evaluation for the redesign of an existing multimedia magazine. Presents the process of model development, structure framing parameters and their components. Demonstrates its application as from the characterization and evaluation of two multimedia magazines, as well as the results such analysis. Concludes by demonstrating that the proposed descriptive-normative model fits the objectives of the study and presents future developments.

\section{Introdução}

Com o surgimento de dispositivos móveis de leitura, como ereaders e tablets, mudanças profundas estão ocorrendo no ecossistema das publicações, e deste modo surgem questionamentos sobre o futuro 
das publicações impressas, indicando novas tendências na criação de conteúdo (BÉHAR, COLOMBANI \& KRISHNAN, 2011).

A este respeito, Agner (2012) afirma que novas práticas de leitura surgiram com o advento destes dispositivos, promovendo um reposicionamento da indústria de mídia e do jornalismo frente a estas novas tecnologias. Um exemplo relatado pelo autor é o lançamento de versões para tablets de diversas publicações brasileiras, como as revistas Veja, Exame, Carta Capital, entre outras.

Nas tablets a interação é feita através de input de interação por gestos, em telas sensíveis ao toque e por prescindir da mediação de dispositivos mecânicos, permite que os usuários interajam com esses dispositivos de forma mais natural (AGNER, 2011).

$\mathrm{O}$ advento do iPad (tablet da Apple) em 2010 mudou consideravelmente o regime das publicações digitais e os editores veem no dispositivo um possível caminho para geração de renda com conteúdo digital (HEIKKILÄ, 2012). Pode-se perceber o lançamento do iPad como um momento de novas possibilidades para as publicações digitais, principalmente pela adoção desta plataforma pela indústria editorial, conforme apontam diversos autores (HEIKKIL ̈̈, 2012; AGNER, 2012; CUNHA \& ARAGÃO, 2011, LOHMAN, ROCHA \& BITARELLO, 2011).

Desde o lançamento do dispositivo tem havido experimentações por parte da indústria editorial, no intuito de compreender as potencialidades desta nova mídia e, assim, definir os novos parâmetros das novas publicações (HEIKKIL̈̈, 2012). Neste sentido faz-se necessária a utilização de instrumentos que possam auxiliar no processo de design, tanto na fase de análise de similares, quanto em fases de avaliação para o design ou redesign de revistas digitais multimídia, permitindo sua caracterização e avaliação.

Sendo um fenômeno recente, verificou-se na literatura uma lacuna no que se refere à caracterização e avaliação de revistas digitais para tablets. Heikkilä (2012) propõe uma categorização levando em consideração os tipos de publicações existentes para este tipo de dispositivo, conforme suas características em termos de formato, experiência do usuário e custos envolvidos na produção, porém apenas dividindo as publicações em categorias (publicações réplicas de impresso; revistas multimídia; e publicações dinâmicas), sem analisá-las especificamente.

Cunha e Aragão (2011) procuraram fazer um levantamento dos elementos de interação das revistas digitais multimídia, mas sua pesquisa se restringiu apenas ao que era apresentado pelas próprias revistas, em suas páginas de ajuda, como elementos de interação.

Considerando esta lacuna e a necessidade de caracterizar e avaliar revistas multimídia dentro de uma pesquisa maior sobre navegação e interação neste tipo de publicação, desenvolveu-se o presente estudo com objetivo principal de propor um modelo descritivo-normativo para caracterização e análise de subsistemas de interação e navegação em revistas digitais multimídia - que, ao longo do artigo, nomearemos 
1 http://www.ivcbrasil.org.br/ Auditorias.asp apenas de "revista multimídia", conforme a categorização proposta por Heikkilä (2012).

Para atingir o objetivo principal, delimitaram-se os seguintes objetivos específicos: (a) identificar elementos de interação e de navegação nas interfaces das revistas multimídia; (b) identificar recomendações para o design de revistas digitais e de interfaces gestuais, aplicáveis às revistas multimídia, relacionadas à interação e/ou navegação neste tipo de publicação; (c) organizar e categorizar estes elementos e recomendações conforme as áreas de interface e sua relação com os subsistemas de interação e de navegação; (d) propor modelo descritivo-normativo para análise de revistas multimídia; (e) verificar a aplicabilidade do modelo a partir da caracterização e avaliação de revistas multimídia de diferentes editoras.

\section{Método}

Para o desenvolvimento deste modelo, em sua primeira fase buscou-se identificar elementos de interação das revistas digitais (CUNHA \& ARAGÃO, 2011), bem como recomendações da literatura aplicáveis ao design de revistas digitais (BUDIU \& NIELSEN, 2011; APPLE, 2012; AGNER, 2013). Para facilitar sua aplicabilidade e análise posterior, tantos os elementos de interação quanto as recomendações selecionadas foram organizados em categorias baseadas na estrutura da revista multimídia e dividas entre os subsistemas de interação e navegação, conforme sua relação mais próxima a estes subsistemas.

Com o intuito de ampliar os elementos de interação e navegação presentes nas interfaces das revistas multimídia, realizou-se um mapeamento para identificar este tipo de publicação comercializadas para iPad na Apple Store. Este mapeamento foi realizado na seguinte ordem: (a) identificação das publicações do tipo "revista" auditadas pelo Instituto Verificador de Circulação (IVC ${ }^{\mathbf{1}}$; (b) identificação da existência de aplicativos correlatos às revistas impressas na Apple Store; (c) classificação das revistas digitais identificadas conforme a categorização proposta por Heikkilä (2012), selecionando as revistas multimídia. Com este processo foram identificadas, em janeiro de 2013, um total de 46 revistas multimídia.

Em seguida, por meio de observação direta de amostras das revistas multimídia selecionadas, foram identificados outros elementos de interação e navegação, além daqueles descritos na literatura consultada. A esta etapa se seguiu a categorização dos elementos de interação e navegação (modelo descritivo) e das recomendações para o design de revistas multimídia (modelo normativo).

Durante o processo de desenvolvimento do modelo descritivo verificou-se que somente a identificação dos elementos de interação presentes na revista multimídia não permitiriam uma caracterização adequada. A estratégia adotada foi analisar separadamente os 
elementos da interface do aplicativo de leitura dos elementos de interface da revista multimídia propriamente dita.

Optou-se também por analisar a interface da revista multimídia, segmentando por tipo de matéria, baseando-se para isso em estudo realizado por Kuhna (2012). Neste estudo o autor analisou matérias de 50 revistas impressas, categorizando-as segundo seus blocos de informação. Deste modo o modelo descritivo correlacionou elementos de interação e navegação com tipos de matérias presentes nas revistas multimídia analisadas.

Nos primeiros testes com o modelo descritivo-normativo verificou-se a necessidade de correlacionar de forma mais próxima ambos os modelos, pois na medida em que os elementos de interação e navegação eram identificados, também se verificavam a aplicabilidade das recomendações do modelo normativo. Com este intuito, aplicou-se a mesma estrutura de enquadramento de parâmetros do modelo descritivo na organização dos critérios de avaliação do modelo normativo para facilitar a análise.

Por fim aplicou-se a primeira versão deste modelo na caracterização e avaliação de duas revistas multimídia de diferentes editoras, com o intuito de verificar a validade do modelo obtido.

\section{Proposta de modelo}

O modelo descritivo-normativo proposto divide-se em identificação da revista multimídia, modelo descritivo e modelo normativo e suas subdivisões. Na Figura 1 apresenta-se uma visão geral do modelo desenvolvido.

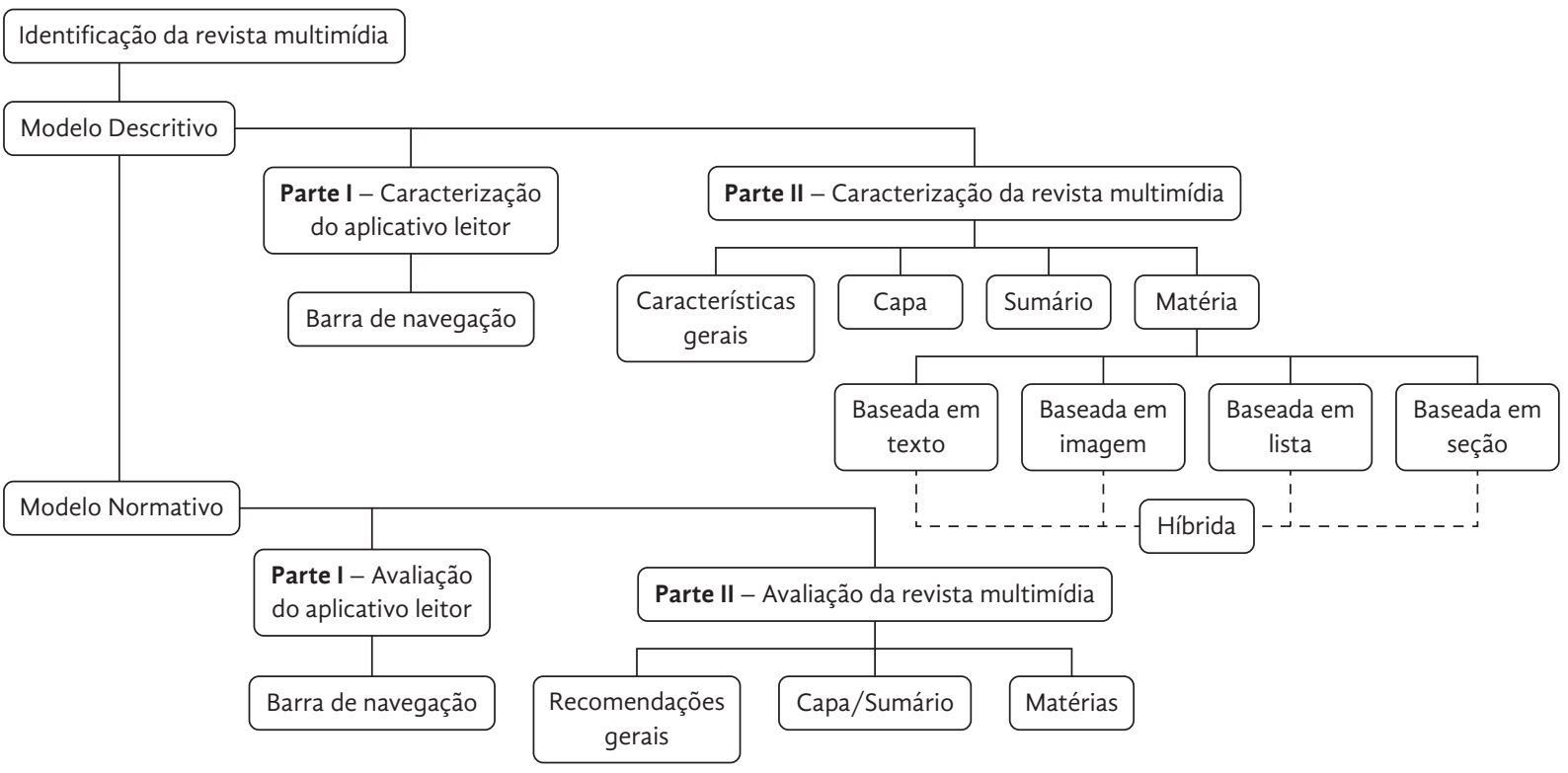

Figura 1 Visão geral do modelo descritivo-normativo (imagem dos autores) 


\subsection{Identificação da revista multimídia}

Tem por objetivo a identificação da revista multimídia analisada e da versão avaliada. Este é um ponto importante em virtude da possibilidade de atualização tanto do aplicativo leitor, quanto da própria revista multimídia.

É composta pelos seguintes elementos:

- Título

- Edição/Data

- Editora

- Segmento

- Periodicidade

- № de páginas

- Versão do aplicativo

- Data de lançamento da versão do aplicativo

\subsection{Definição do modelo descritivo}

O modelo descritivo divide-se em duas partes principais: características do aplicativo leitor e características da revista multimídia.

\subsubsection{Parte I-Características do aplicativo leitor}

Inicia-se a análise da revista multimídia verificando os elementos/ recursos presentes na barra de navegação. Esta barra de navegação é a parte da interface do aplicativo leitor que fica disponível no momento da leitura e é a mesma para todas as edições, além de eventualmente passar por atualizações em novas versões do aplicativo. Os elementos analisados podem ser vistos na Figura 2.

\subsubsection{Parte II - Características da revista multimídia}

Compreende os elementos de interação e navegação presentes na interface da própria revista e ao contrário da barra de navegação, não sofrem alteração quando o aplicativo é atualizado. A análise é iniciada verificando-se características gerais da publicação, seu esquema de navegação e forma de acesso à barra/opções de navegação do aplicativo de leitura (Figura 3).

A análise da interface da revista compreende a análise de suas páginas e matérias, havendo uma distinção entre a capa e a página de sumário e as demais matérias. Apesar dos elementos para a caracterização serem os mesmos, a capa e o sumário não se enquadram nos tipos de matéria definidos por Khuna (2012), conforme será detalhado adiante. 


\begin{tabular}{|l|l|}
\hline \multicolumn{2}{|l|}{ Barra de navegação } \\
\hline \multirow{2}{*}{ Nubsistema de navegação } \\
\cline { 2 - 3 } & \multicolumn{2}{|c|}{ Navegar pelo índice (lateral) } & \\
\hline Navegão (slider) & \\
\hline Avançar & \\
\hline Retornar & \\
\hline Ir para o sumário & \\
\hline Ir para capa & \\
\hline Ir para ajuda/maniaturas) & \\
\hline Ir para edições (adquirida e novas) & \\
\hline Ir para edições adquiridas & \\
\hline Comprar novas edições & \\
\hline Ir para site/blog & \\
\hline \multicolumn{2}{|c|}{ Subsistema de interação } \\
\hline
\end{tabular}

Figura 2 Elementos de caracterização do aplicativo leitor (imagem dos autores)

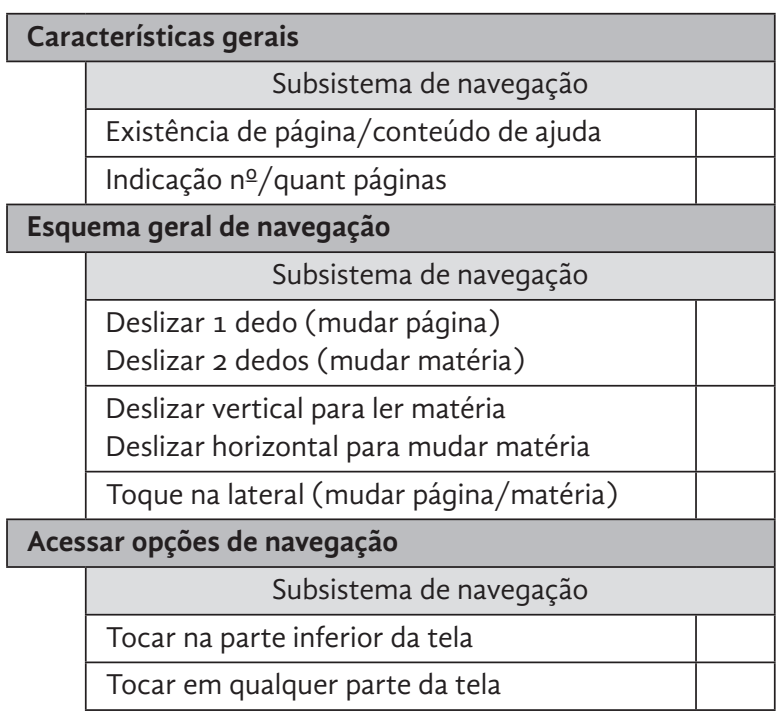

Figura 3 Elementos para caracterização de aspectos gerais da revista multimídia (imagem dos autores)

A título de demonstração, na Figura 4 apresentam-se os elementos de caracterização analisados na capa da revista multimídia, utilizados da mesma forma na caracterização da página de sumário. 


\begin{tabular}{|c|c|c|}
\hline \multicolumn{3}{|l|}{ Capa } \\
\hline \multicolumn{3}{|c|}{ Subsistema de navegação } \\
\hline \multicolumn{2}{|c|}{ Orientação de leitura $(\mathrm{H} / \mathrm{V} / \mathrm{A})$} & \\
\hline \multicolumn{2}{|c|}{ Orientação analisada (H/V) } & \\
\hline \multirow[t]{2}{*}{ Girar o iPad } & Acessar layout alternativo & \\
\hline & Acessar conteúdo extra & \\
\hline \multirow[t]{3}{*}{ Acionar link } & Acessar conteúdos externos & \\
\hline & Navegar entre páginas & \\
\hline & Navegar intrapágina & \\
\hline \multirow{5}{*}{$\begin{array}{l}\text { Navegar no } \\
\text { conteúdo }\end{array}$} & Rolagem de texto & \\
\hline & Galeria de fotos/slideshow & \\
\hline & Navegar na imagem (panorama) & \\
\hline & Imagem $360^{\circ}$ & \\
\hline & Ampliar imagem/conteúdo & \\
\hline \multicolumn{3}{|c|}{ Subsistema de interação } \\
\hline \multirow[t]{3}{*}{ Executar } & Vídeo & \\
\hline & Áudio & \\
\hline & Animação & \\
\hline
\end{tabular}

Figura 4 Caracterização da capa da revista multimídia (imagem dos autores)

Após a caracterização da capa e da página de sumário, é feita a análise das páginas das revistas, conforme a classificação das matérias, definido por Kuhna (2012):

- Matéria baseada em texto: matéria típica com foco no corpo de texto. Pode incluir uma ou mais imagens, que podem ter uma ordem definida.

- Matéria baseada em imagem: matéria curta com foco em uma grande imagem, que é usualmente usada como um elemento de background;
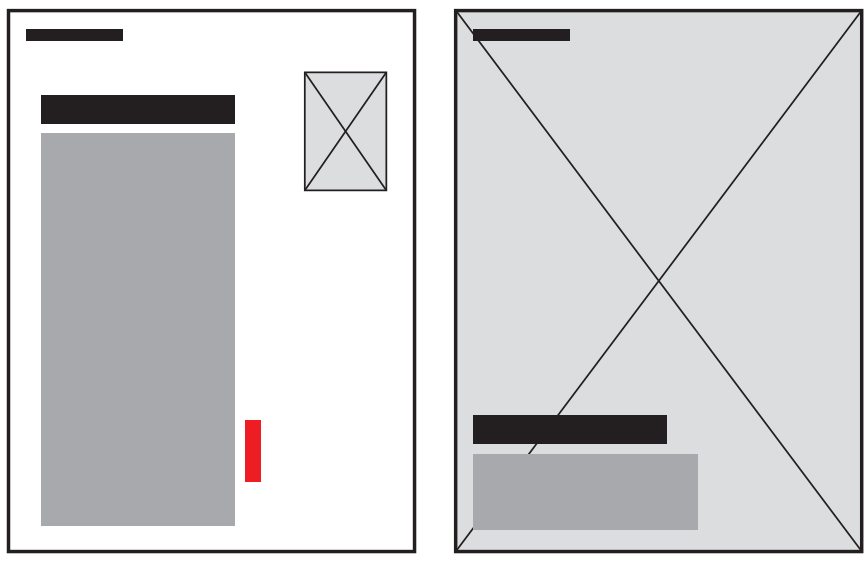

Legenda:

Título/vinheta

Texto

$\bigotimes$ Imagem

Área/indicação de interação

Figura 5 Representação de layout utilizado na revista Pais \& Filhos para matéria do tipo Texto (esq.) e do tipo Imagem (dir.) (imagem dos autores) 
- Matéria baseada em lista: matéria com algum tipo de listagem com múltiplos elementos na página (elementos recorrentes);

- Matéria baseada em seção: uma matéria que consiste de múltiplos sub-artigos.
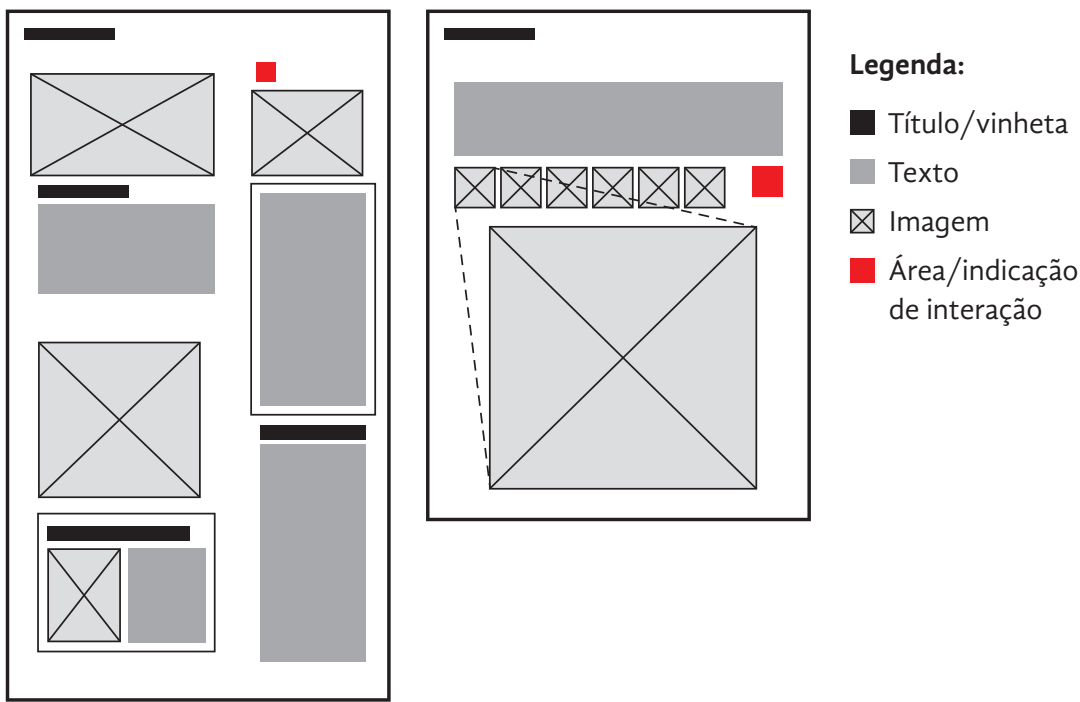

Figura 6 Representação de layout utilizado na revista Pais \& Filhos para matéria do tipo Texto (esq.) e do tipo Imagem (dir.) (imagem dos autores)

Um quinto tipo de matéria foi necessário para abranger algumas matérias que se apresentam de um tipo em seu início, mas que se modificam ao longo do conteúdo. Este tipo de matéria foi denominado "matéria híbrida" (Figura 7).

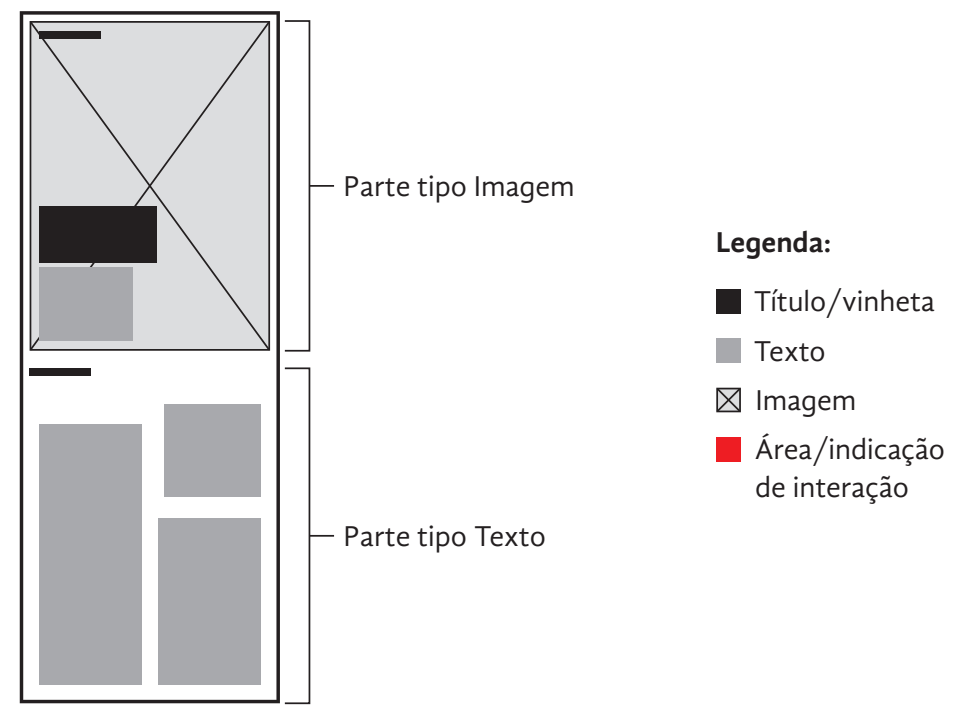

Figura 7 Representação de layout utilizado na revista Pais \& Filhos para matérias híbridas (imagem dos autores) 
Cada matéria é analisada individualmente, mas o registro da análise é feito em fichas separadas por tipo de matéria (Figura 8).

\begin{tabular}{|c|c|c|c|c|c|c|c|c|c|c|c|c|}
\hline \multicolumn{2}{|c|}{ Matéria baseada em texto $(T)$} & \multicolumn{11}{|c|}{ Matérias } \\
\hline \multicolumn{2}{|c|}{ Subsistema de navegação } & 4 & 7 & 16 & $\ldots$ & $\ldots$ & $\ldots$ & $\ldots$ & $\ldots$ & $\ldots$ & $\ldots$ & $\mathrm{n}$ \\
\hline \multicolumn{13}{|c|}{ Orientação de leitura (H/V/A) } \\
\hline \multicolumn{13}{|c|}{ Orientação analisada (H/V) } \\
\hline \multirow[t]{2}{*}{ Girar o iPad } & Acessar layout alternativo & & & & & & & & & & & \\
\hline & Acessar conteúdo extra & & & & & & & & & & & \\
\hline \multirow[t]{3}{*}{ Acionar link } & Acessar conteúdos externos & & & & & & & & & & & \\
\hline & Navegar entre páginas & & & & & & & & & & & \\
\hline & Navegar intrapágina & & & & & & & & & & & \\
\hline \multirow{5}{*}{$\begin{array}{l}\text { Navegar no } \\
\text { conteúdo }\end{array}$} & Rolagem de texto & & & & & & & & & & & \\
\hline & Galeria de fotos/slideshow & & & & & & & & & & & \\
\hline & Navegar na imagem (panorama) & & & & & & & & & & & \\
\hline & Imagem $360^{\circ}$ & & & & & & & & & & & \\
\hline & Ampliar imagem & & & & & & & & & & & \\
\hline \multicolumn{13}{|c|}{ Subsistema de interação } \\
\hline \multirow[t]{3}{*}{ Executar } & Vídeo & & & & & & & & & & & \\
\hline & Áudio & & & & & & & & & & & \\
\hline & Animação & & & & & & & & & & & \\
\hline
\end{tabular}

Figura 8 Caracterização de matérias do tipo Texto (imagem dos autores)

À matéria analisada é atribuído um número sequencial, que corresponde à posição da página ou matéria na sequência de leitura, e que fica anotado na ficha de caracterização correspondente ao tipo de matéria. Este procedimento é necessário para futuras consultas, pois não é comum que a revista multimídia seja paginada, tal como na revista impressa.

\subsection{Definição do modelo normativo}

Para a elaboração deste modelo partiu-se inicialmente das recomendações de Budiu e Nielsen (2011) e da Apple (2012), ambas tratando da interação no iPad, filtrando-se, no entanto, as recomendações aplicáveis ao contexto das revistas multimídia.

Posteriormente complementou-se o modelo com alguns requisitos de design para a produção de conteúdos jornalísticos em tablets, propostos por Agner (2013).

Para cada recomendação/requisito, definiu-se a possibilidade dos seguintes valores:

- Atende: atende o requisito na sua totalidade, ao longo de toda a revista multimídia; 
- Atende parcialmente: atende na maior parte da revista, mas apresenta divergência em alguns pontos;

- Não atende: não atende a recomendação/requisito em sua totalidade ou quase totalidade (a transgressão é muito mais comum que o atendimento);

- Não aplicável: quando não foi detectado em toda a revista multimídia a possibilidade de aplicação da recomendação (e. g. para que se atenda uma recomendação sobre uma janela modal é necessário que se utilize este recurso).

Tendo selecionado as recomendações e requisitos, passou-se a uma etapa de categorização, estabelecendo uma correlação entre os elementos do modelo normativo com os elementos do modelo descritivo.

Deste modo o modelo normativo apresenta duas partes, sendo que na primeira parte é avaliado a interação e navegação na interface do aplicativo de leitura e na segunda parte, na interface da revista. Para cada recomendação adotada atribuiu-se um código no formato Nxx, (onde xx é uma numeração sequencial), que servirá para correlacionar os relatos de transgressões encontradas com a respectiva recomendação.

Apresenta-se a seguir, as duas partes do modelo normativo e seus componentes (Figuras 9, 10, 11 e 12).

\subsubsection{Parte I - Avaliação do aplicativo leitor}

\begin{tabular}{|c|c|c|c|c|c|c|}
\hline \multicolumn{3}{|c|}{ Barra de navegação } & \multirow[t]{2}{*}{$\mathrm{A}$} & \multirow[t]{2}{*}{$\mathrm{P}$} & \multirow[t]{2}{*}{$\mathrm{N}$} & \multirow[t]{2}{*}{$\mathrm{N} / \mathrm{A}$} \\
\hline N1 & \multirow{6}{*}{ 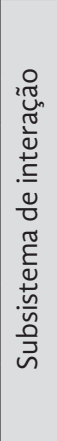 } & $\begin{array}{l}\text { A configuração gráfica (ícones ou rótulos) de um elemento da interface do } \\
\text { aplicativo deve deixar explícita a ação desencadeada por seu acionamento. }\end{array}$ & & & & \\
\hline N2 & & Os controles do aplicativo devem aparecer assim que o usuário toque na tela. & & & & \\
\hline N3 & & $\begin{array}{l}\text { Os controles do aplicativo devem desaparecer assim que o usuário tenha encerrado } \\
\text { a interação com eles. }\end{array}$ & & & & \\
\hline N4 & & $\begin{array}{l}\text { As revistas digitais devem, preferencialmente, possuir controles customizados } \\
\text { integrados a seu estilo gráfico. }\end{array}$ & & & & \\
\hline N5 & & $\begin{array}{l}\text { Os controles de ações padronizadas do sistema operacional não devem ter sua } \\
\text { aparência redicalmente modificada (e. g., lixeira para excluir). }\end{array}$ & & & & \\
\hline N6 & & $\begin{array}{l}\text { Os links e botões devem ser colocados com distâncias adequadas uns dos outros } \\
\text { para evitar toques acidentais. }\end{array}$ & & & & \\
\hline N7 & \multirow{6}{*}{ 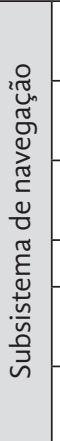 } & $\begin{array}{l}\text { A barra de navegação da interface do aplicativo deve apresentar um índice com } \\
\text { links para os conteúdos. }\end{array}$ & & & & \\
\hline N8 & & $\begin{array}{l}\text { Navegadores de páginas do tipo slider não devem ser utilizados por serem pouco } \\
\text { precisos e por serem difíceis de usar. }\end{array}$ & & & & \\
\hline N9 & & $\begin{array}{l}\text { A interface da revista deve possuir um botão ou recurso de retronavegação, } \\
\text { permitindo desfazer toques acidentais. }\end{array}$ & & & & \\
\hline N10 & & O botão ou recurso de retronavegação deve atuar em todas as páginas da revista. & & & & \\
\hline \multirow[t]{2}{*}{ N11 } & & $\begin{array}{l}\text { A interface da revista ou do aplicativo de leitura deve ter um link direto para a capa } \\
\text { ou para a página de sumário. }\end{array}$ & & & & \\
\hline & & $\begin{array}{l}\text { O ícone ou link do sumário na barra de navegação deve levar o usuário diretamente } \\
\text { para a página de sumário da revista. }\end{array}$ & & & & \\
\hline
\end{tabular}

Figura 9 Critérios para avaliação da barra de navegação (imagem dos autores) 


\subsubsection{Parte II - Avaliação da interface da revista}

\begin{tabular}{|c|c|c|c|c|c|c|}
\hline \multicolumn{3}{|c|}{ Recomendações gerais } & \multirow[t]{2}{*}{ A } & \multirow[t]{2}{*}{$\mathrm{P}$} & \multirow[t]{2}{*}{$\mathrm{N}$} & \multirow[t]{2}{*}{ N/A } \\
\hline N13 & \multirow{6}{*}{ 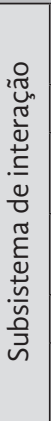 } & $\begin{array}{l}\text { As instruções para a utilização da revista digital devem se restringir apenas àquelas } \\
\text { necessárias para o usuário iniciar a leitura. }\end{array}$ & & & & \\
\hline N14 & & As instruções para a utilização da revista digital devem ser simples e claras. & & & & \\
\hline N15 & & $\begin{array}{l}\text { A interface da revista digital deve prover affordances que permitam a identificação } \\
\text { de áreas sensíveis e de interação. }\end{array}$ & & & & \\
\hline N16 & & $\begin{array}{l}\text { A configuração gráfica (ícones ou rótulos) de um elemento da interface da revista } \\
\text { deve deixar explícita a ação desencadeada por seu acionamento. }\end{array}$ & & & & \\
\hline N17 & & A revista deve responder sempre da mesma forma a um determinado gesto. & & & & \\
\hline N18 & & $\begin{array}{l}\text { Recursos utilizados comumente em páginas web (e. g. busca, botão voltar, links) } \\
\text { devem se comportar da mesma maneira que na web. }\end{array}$ & & & & \\
\hline N19 & \multirow{8}{*}{ 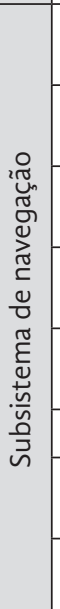 } & $\begin{array}{l}\text { A revista digital deve ser capaz de iniciar na orientação em que o usuário está } \\
\text { utilizando o dispositivo de leitura. }\end{array}$ & & & & \\
\hline N2O & & $\begin{array}{l}\text { A revista digital deve ser capaz de ser reproduzida na orientação em que o usuário } \\
\text { está utilizando o dispositivo de leitura. }\end{array}$ & & & & \\
\hline N21 & & $\begin{array}{l}\text { Uma revista que foi fechada, ao ser reiniciada, deverá restaurar o estado em que se } \\
\text { encontrava, para que o usuário possa continuar sua leitura de onde parou. }\end{array}$ & & & & \\
\hline N22 & & $\begin{array}{l}\text { As páginas da revista devem conter espaço suficiente nas laterais para a mudança } \\
\text { de página sem interferir em outras áreas sensíveis (sobreposição de comandos). }\end{array}$ & & & & \\
\hline N23 & & $\begin{array}{l}\text { A interface da revista digital deve fornecer as pistas necessárias (setas, dicas) para } \\
\text { que o usuário navegue adequadamente utilizando o gesto de arrastar. }\end{array}$ & & & & \\
\hline N24 & & Links devem ser claramente diferenciados do restante da interface. & & & & \\
\hline N25 & & $\begin{array}{l}\text { A revista digital deve prover feedback imediato das ações dos usuários (quando um } \\
\text { controle é operado). }\end{array}$ & & & & \\
\hline N26 & & $\begin{array}{l}\text { A revista digital deve prover feedback do processamento das ações dos usuários } \\
\text { (principalmente em ações longas). }\end{array}$ & & & & \\
\hline
\end{tabular}

Figura 10 Recomendações gerais aplicáveis em todas as páginas/matérias da revista multimídia (imagem dos autores)

\begin{tabular}{|c|c|c|c|c|c|c|}
\hline \multicolumn{3}{|c|}{ Capa/Sumário } & \multirow[t]{2}{*}{ A } & \multirow[t]{2}{*}{$P$} & \multirow[t]{2}{*}{$\mathrm{N}$} & \multirow[t]{2}{*}{ N/A } \\
\hline N27 & 竞。 & $\begin{array}{l}\text { A capa ou a página de sumário devem atuar de forma similar a uma home page, } \\
\text { direcionando os leitores para os conteúdos. }\end{array}$ & & & & \\
\hline N28 & 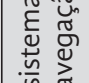 & $\begin{array}{l}\text { As informações presentes na página de sumário devem ser auto explicativas e } \\
\text { claramente formatadas, de modo a auxiliar o leitor a decidir qual matéria ler. }\end{array}$ & & & & \\
\hline N29 & $\stackrel{0}{n}=$ & $\begin{array}{l}\text { A revista deve possuir uma página de sumário que direcione o usuário para a } \\
\text { matéria de sua escolha. }\end{array}$ & & & & \\
\hline
\end{tabular}

Figura 11 Recomendações para a capa e página de sumário da revista multimídia (imagem dos autores) 


\begin{tabular}{|c|c|c|c|c|c|c|}
\hline \multicolumn{3}{|c|}{ Recomendações gerais } & \multirow[t]{2}{*}{$\mathrm{A}$} & \multirow[t]{2}{*}{$\mathrm{P}$} & \multirow[t]{2}{*}{$\mathrm{N}$} & \multirow[t]{2}{*}{ N/A } \\
\hline N3O & \multirow{4}{*}{ 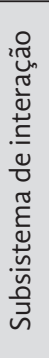 } & $\begin{array}{l}\text { Tarefas modais devem ser curtas e focadas (e. g., assistir um vídeo, responder } \\
\text { uma pesaquisa). }\end{array}$ & & & & \\
\hline N31 & & $\begin{array}{l}\text { As janelas modais devem apresentar uma forma óbvia e segura para sair da janela } \\
\text { ao encerrar uma tarefa. }\end{array}$ & & & & \\
\hline N32 & & $\begin{array}{l}\text { Quando uma popover apresentar opções de interação, as informações desta } \\
\text { interação devem ser suficientemente detalhadas para que o leitor possa tomar } \\
\text { uma decisão. }\end{array}$ & & & & \\
\hline N33 & & $\begin{array}{l}\text { A revista deve apresentar consistência em sua forma de interação (e. g. mesma } \\
\text { característica gráfica para indicar pontos de interação). }\end{array}$ & & & & \\
\hline N34 & \multirow{5}{*}{ 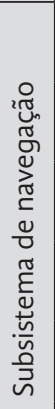 } & $\begin{array}{l}\text { A interface da revista não deve conter carrosséis e outros elementos que possam } \\
\text { conflitar com o gesto de arrastar para mudança de páginas. }\end{array}$ & & & & \\
\hline N35 & & $\begin{array}{l}\text { Listas de opções devem ser acionáveis em toda a extensão da linha e não apenas no } \\
\text { texto/ícone. }\end{array}$ & & & & \\
\hline N36 & & $\begin{array}{l}\text { O usuário deve ser informado sobre a necessidade de mudar a orientação do } \\
\text { dispositivo de leitura para acessar conteúdo extra. }\end{array}$ & & & & \\
\hline N37 & & $\begin{array}{l}\text { O leitor deve retornar sempre ao mesmo ponto de leitura quando mudar a orientação } \\
\text { de leitura. Neste caso, a leitura não deve remeter o leitor ao início da matéria. }\end{array}$ & & & & \\
\hline N38 & & $\begin{array}{l}\text { A interface da revista deve possuir marcadores/indicações que auxiliem os usuários } \\
\text { na localização dentro do ambiente virtual. }\end{array}$ & & & & \\
\hline N39 & & $\begin{array}{l}\text { A interface da revista deve possuir marcadores/indicações que auxiliem os usuários } \\
\text { no retorno dos seus passos. }\end{array}$ & & & & \\
\hline
\end{tabular}

Figura 12 Recomendações para as demais matérias da revista multimídia (imagem dos autores)

\section{Aplicação do modelo proposto}

Concluída a primeira versão do modelo proposto, passou-se a sua aplicação na caracterização e avaliação de duas revistas multimídia, as revistas Pais \& Filhos e EmbalagemMarca. Por se tratar de um teste da aplicação do modelo descritivo-normativo desenvolvido, estas revistas foram selecionadas em função da conveniência e facilidade de acesso.

Apresenta-se a seguir o resultado da aplicação do modelo descritivo-normativo em ambas as revistas, conforme cada uma de suas partes.

\subsection{Identificação da revista multimídia}

Na Tabela 1 são apresentados os dados de identificação das revistas analisadas.

Tabela 1 Identificação das revistas multimídia analisadas

\begin{tabular}{lll}
\hline & Revista 1 & Revista 2 \\
\hline Título & Pais \& Filhos & EmbalagemMarca \\
Edição /Data & Ano 44/nำ 514-Abril/2013 & Ano XIV/no 165-Maio/2013 \\
Editora & Manchete & Bloco Comunicações \\
\hline
\end{tabular}


Tabela 1 Identificação das revistas multimídia analisadas

(Conclusão)

\begin{tabular}{lll}
\hline & Revista 1 & Revista 2 \\
\hline Segmento & Bebês & Embalagens \\
Periodicidade & Mensal & Mensal \\
№ de páginas & 40 & 18 \\
Versão do aplicativo & 2.5 & 2.0 \\
Data da versão & $08 / 05 / 2013$ & $12 / 03 / 2013$ \\
\hline
\end{tabular}

\subsection{Aplicação do modelo descritivo}

\subsubsection{Parte I-Características do aplicativo leitor}

Na Tabela 2 são apresentados os resultados das análises de ambas as revistas em relação à barra de navegação do aplicativo leitor.

Tabela 2 Caracterização do aplicativo leitor das revistas multimídia analisadas

\begin{tabular}{lll}
\hline & Pais \& Fllhos & EmbalagemMarca \\
\hline Barra de navegação & & \\
\hline Subsistema de navegação & & \\
\hline Navegar pelo índice (do aplicativo) & Presente & Presente \\
Navegar pela edição (uso de slider) & Ausente & Ausente \\
Navegar pela edição (uso de miniaturas) & Presente & Presente \\
Avançar & Ausente & Ausente \\
Retornar & Presente & Presente \\
Ir para sumário & Ausente & Ausente \\
Ir para capa da edição & Presente & Ausente \\
Ir para Ajuda/Manual & Ausente & Ausente \\
Ir para edições (adquiridas e novas) & Presente & Presente \\
Ir para edições adquiridas & Ausente & Ausente \\
Comprar novas edições & Ausente & Ausente \\
\hline Subsistema de interação & & Presente \\
\hline Ir para site/blog da revista & Ausente & Presente \\
Marcador /favorito & Presente & Ausente \\
Compartilhar & Presente \\
\hline
\end{tabular}

Analisando os resultados apresentados na Tabela 2, verifica-se a utilização de quase os mesmos recursos por ambas as revistas. apesar de não haver indicação nas revistas a respeito da tecnologia utilizada no desenvolvimento do aplicativo, é possível supor que ambas as revistas utilizam a mesma tecnologia de desenvolvimento de revistas 
multimídia. É provável que se trate de sistema proprietário, com limitação de personalização do aplicativo.

\subsubsection{Parte II - Características da revista multimídia}

Na segunda parte são analisados as características gerais da revista multimídia e individualmente cada uma de suas matérias.

Em termos de características gerais, percebe-se que ambas as revistas possuem conteúdo de ajuda, mas apenas a Pais \& Filhos númera suas páginas (em algumas matérias) como forma de auxílio ao leitor. Para navegar nos conteúdos, ambas as revistas utilizam um modelo baseado em deslizar na vertical para ler a matéria e deslizar na horizontal para mudar de matéria. A revista EmbalagemMarca, como uma forma adicional de navegação, utiliza o toque na lateral das páginas como recurso de navegação entre matérias.

Tabela 3 Caracterização do aplicativo leitor das revistas multimídia analisadas

\begin{tabular}{|c|c|c|}
\hline & Pais \& Fllhos & EmbalagemMarca \\
\hline \multicolumn{3}{|l|}{ Características gerais } \\
\hline Existência de página /conteúdo de ajuda & Presente & Presente \\
\hline Indicação de páginas & Presente & Ausente \\
\hline \multicolumn{3}{|l|}{ Modelo conceitual de navegação: } \\
\hline $\begin{array}{l}\text { Deslizar } 1 \text { dedo para mudar de página e } \\
2 \text { dedos para mudar de matéria }\end{array}$ & Não utilizado & Não utilizado \\
\hline $\begin{array}{l}\text { Deslizar na vertical para ler matéria e na } \\
\text { horizontal para mudar de matéria }\end{array}$ & Modelo utilizado & Modelo utilizado \\
\hline Toque na lateral para mudar de matéria & Não utilizado & Modelo utilizado \\
\hline \multicolumn{3}{|l|}{ Forma de acesso à barra de navegação } \\
\hline Tocar na parte inferior da tela (apenas) & Não utilizado & Modelo utilizado \\
\hline Tocar em qualquer parte da tela & Modelo utilizado & Não utilizado \\
\hline
\end{tabular}

Na sequência à análise geral faz-se a análise das capas e sumários. O resultado comparativo desta análise pode ser verificado na Tabela 4 .

Em termos de orientação, verifica-se uma maior flexibilidade por parte da revista Pais \& Filhos que permite a leitura da capa e do sumário em ambas as orientações. A opção de análise na orientação vertical se deve a ser este a principal orientação de leitura das revistas multimídia, sendo feito a análise da página na orientação horizontal apenas quando esta é a única opção da revista (critério utilizado para todas as páginas analisadas). No caso da revista EmbalagemMarca verifica-se a utilização de apenas uma orientação de leitura, que é o padrão adotado para toda a revista. 
Tabela 4 Caracterização das capas e sumários das revistas Pais \& Filhos e EmbalagemMarca

\begin{tabular}{|c|c|c|c|c|c|}
\hline \multirow{2}{*}{$\begin{array}{l}\text { Revista } \\
\text { Página }\end{array}$} & & \multicolumn{2}{|c|}{ Pais \& Filhos } & \multicolumn{2}{|c|}{ EmbalagemMarca } \\
\hline & & Capa & Sumário & Capa & Sumário \\
\hline Orientação de leitura & & Ambas & Ambas & Vertical & Vertical \\
\hline Orientação analisada & & Vertical & Vertical & Vertical & Vertical \\
\hline \multirow[t]{2}{*}{ Girar o iPad } & Acessar layout alternativo & Presente & Presente & Ausente & Ausente \\
\hline & Acessar conteúdo extra & Ausente & Ausente & Ausente & Ausente \\
\hline \multirow[t]{3}{*}{ Acionar link } & Acessar conteúdos externos & Ausente & Ausente & Ausente & Ausente \\
\hline & Navegar entre páginas & Presente & Presente & Ausente & Presente \\
\hline & Navegar intrapágina & Ausente & Ausente & Ausente & Ausente \\
\hline \multirow[t]{5}{*}{ Navegar no conteúdo } & Rolagem de texto & Ausente & Ausente & Ausente & Ausente \\
\hline & Galeria de fotos/slideshow & Ausente & Ausente & Ausente & Ausente \\
\hline & Navegar na imagem & Ausente & Ausente & Ausente & Ausente \\
\hline & Imagem $360^{\circ}$ & Ausente & Ausente & Ausente & Ausente \\
\hline & Ampliar imagem & Ausente & Ausente & Ausente & Ausente \\
\hline \multirow[t]{3}{*}{ Executar } & Vídeo & Ausente & Ausente & Ausente & Ausente \\
\hline & Áudio & Ausente & Ausente & Ausente & Ausente \\
\hline & Animação & Ausente & Ausente & Ausente & Ausente \\
\hline
\end{tabular}

Em relação aos demais recursos, verifica-se que a maioria dos recursos de interação e navegação disponíveis não são utilizados, resumindo-se a direcionar o leitor aos conteúdos da revista. No caso da revista EmbalagemMarca apenas o sumário apresenta esta possibilidade.

De forma a não se estender muito, apresentamos na Tabela 5 os dados compilados da caracterização da revista Pais \& Filhos, para cada tipo de matéria identificada e os elementos de interação presentes. A forma de análise é a mesma apresentada acima para as páginas da capa e do sumário.

Primeiramente verifica-se uma predominância da matérias dos tipos Texto e Imagem. A orientação de leitura varia ao longo da revista, obrigando o usuário a girar o iPad em diversos momentos. Algumas páginas possuem dupla orientação, mas para a maioria a orientação de leitura é a vertical. Pode-se verificar que é nas matérias do tipo Imagem que se concentram a maior parte da dupla orientação de leitura, provavelmente em virtude da facilidade em se formatar um segundo layout. Esta possibilidade de dupla orientação de leitura foi utilizada apenas para possibilitar um layout alternativo e em nenhum dos casos apresentou-se conteúdo extra ao usuário.

Em relação aos recursos de navegação e interação presentes, o mais utilizado foi o de rolagem de texto (principalmente nas matérias do tipo Texto), seguido pela navegação intrapágina. A navegação intrapágina é aqui considerada como toda forma de navegação dentro 
do própria página, inclusive para se acessar conteúdos extras como notas de textos, por exemplo.

Em menor quantidade foram utilizados recursos de galeria de fotos/slideshows (em 3 páginas), vídeos (3 páginas), ampliação de imagem ( 2 páginas) e imagem $360^{\circ}$ (1 página). Os registros apresentados demonstram a presença de determinado tipo de interação em determinado tipo de página, mas não a quantidade em que foi utilizado.

Tabela 5 Caracterização das matérias da revista Pais \& Filhos

\begin{tabular}{|c|c|c|c|c|c|c|c|}
\hline \multirow{2}{*}{$\begin{array}{l}\text { Revista } \\
\text { Matéria baseada em }\end{array}$} & & \multicolumn{6}{|c|}{ Pais \& Filhos } \\
\hline & & Texto & Imagem & Seção & Lista & Híbrida & Total \\
\hline Páginas por tipo & & 9 & 12 & 2 & 4 & 3 & 30 \\
\hline \multirow[t]{3}{*}{ Orientação de leitura } & Horizontal & 0 & 0 & 1 & 0 & 2 & 03 \\
\hline & Vertical & 6 & 4 & 1 & 4 & 1 & 16 \\
\hline & Ambas & 3 & 8 & 0 & 0 & 0 & 11 \\
\hline \multirow[t]{2}{*}{ Orientação analisada } & Horizontal & 0 & 0 & 1 & 0 & 2 & 03 \\
\hline & Vertical & 9 & 12 & 1 & 4 & 1 & 27 \\
\hline \multirow[t]{2}{*}{ Girar o iPad } & Acessar layout alternativo & 3 & 8 & 0 & 0 & 0 & 11 \\
\hline & Acessar conteúdo extra & 0 & 0 & 0 & 0 & 0 & 0 \\
\hline \multirow[t]{3}{*}{ Acionar link } & Acessar conteúdos externos & 5 & 5 & 0 & 3 & 3 & 16 \\
\hline & Navegar entre páginas & 0 & 0 & 0 & 0 & 0 & 0 \\
\hline & Navegar intrapágina & 0 & 5 & 2 & 2 & 2 & 11 \\
\hline \multirow[t]{5}{*}{ Navegar no conteúdo } & Rolagem de texto & 8 & 1 & 0 & 3 & 1 & 13 \\
\hline & Galeria de fotos/slideshow & 0 & 2 & 0 & 0 & 1 & 3 \\
\hline & Navegar na imagem & 0 & 0 & 0 & 0 & 0 & 0 \\
\hline & Imagem $360^{\circ}$ & 0 & 1 & 0 & 0 & 0 & 1 \\
\hline & Ampliar imagem & 0 & 1 & 1 & 0 & 0 & 2 \\
\hline \multirow[t]{3}{*}{ Executar } & Vídeo & 1 & 1 & 0 & 2 & 0 & 3 \\
\hline & Áudio & 0 & 0 & 0 & 0 & 0 & 0 \\
\hline & Animação & 0 & 0 & 0 & 0 & 0 & 0 \\
\hline
\end{tabular}

Ainda analisando os dados obtidos, por parte da matéria do tipo Imagem, pode-se constatar maiores possibilidades de interação do usuário com a revista, pois apresentou maior variedade de elementos de interação que os demais tipos de matéria.

\subsection{Aplicação do modelo normativo}

Ao longo do processo de caracterização das revistas selecionadas, realizou-se também as avaliações dos subsistemas de interação e navegação. Como cada parte da estrutura de enquadramento de 
parâmetros possui relação direta entre os modelos, ao se caracterizar, por exemplo, a barra de navegação, é necessário identificar e testar a interação dos elementos presentes. Por consequência verifica-se o atendimento às recomendações para esta parte da interface.

No modelo avaliativo, o objetivo é a identificação de pontos positivos e negativos da revista multimídia, em termos de navegação e interação, segundo cada uma das recomendações adotadas. A avaliação busca também identificar pontos problemáticos a serem evitados em um novo projeto, ou ainda, a correção destes problemas em um possível redesign.

Desta forma, é importante que sejam registradas observações ou comentários quando identificado uma transgressão parcial (P) ou total $(\mathrm{N})$, para uma análise posterior, mencionando qual recomendação não foi atendida, um breve resumo da transgressão e a indicação de algumas páginas onde a transgressão ocorreu, como exemplo. Este registro deve ser feito também quando se encontra um ponto positivo que deva fazer parte do design ou redesign de uma revista multimídia.

Como o objetivo deste estudo é apresentar o modelo descritivonormativo e demonstrar sua utilização, apresentamos na Tabela 6 um exemplo da compilação destes dados para a revista Pais \& Filhos.

Tabela 6 Amostra do registro de transgressões às recomendações do modelo normativo

\begin{tabular}{|c|c|c|}
\hline Item & Descrição da transgressão & Matéria(s) \\
\hline N16 & $\begin{array}{l}\text { O ícone "+" indica a existência de conteúdo extra, mas não } \\
\text { explicita se será aberto uma janela modal, um navegador dentro } \\
\text { do aplicativo ou um navegador em um outro aplicativo. }\end{array}$ & 19 \\
\hline N15 & $\begin{array}{l}\text { Os pontos de interação não estão identificados. Um ícone indica } \\
\text { as áreas de interação indiretamente, orientando como proceder } \\
\text { para acioná-las. }\end{array}$ & $17,19,27$ \\
\hline N33 & $\begin{array}{l}\text { A revista apresenta as seguintes inconsistências na interação: } \\
\text { a) Acesso a conteúdo em sites: ora é aberto em um } \\
\text { navegador externos, ora em um navegador incorporado; } \\
\text { b) Indicação de conteúdo extra em sites: para direcionar o } \\
\text { usuário para estes conteúdos foram utilizados um ícone "+", } \\
\text { um ícone de mouse e símbolo da revista; } \\
\text { c) Símbolo da revista: em algumas matérias aciona alguma ação, } \\
\text { em outros não acionada nada. } \\
\text { d) Janelas modais: após aberta, tocando no ícone "+", em alguns } \\
\text { casos para fechar basta um toque em qualquer parte da tela, } \\
\text { em outros tem que tocar novamente no ícone "+" }\end{array}$ & $\begin{array}{l}\text { a) } 7,8 \\
\text { b) } 7,19,21 \\
\text { c) } 7,9,11 \\
\text { d) } 4,24,26\end{array}$ \\
\hline
\end{tabular}

A análise dos dados obtidos pode ser feita através da compilação dos resultados para cada segmento do modelo, obtendo-se assim um panorama geral das revistas analisadas em relação ao total de recomendações do modelo normativo. 
Na tabela 7, por exemplo, têm-se um comparativo entre os segmentos analisados, bem como entre as revistas. Verifica-se claramente que o subsistema de navegação é mais problemático em ambas as revistas, necessitando um maior cuidado nas etapas de design relacionadas à navegação da revista multimídia, ou, em caso de redesign, indicam onde os esforços de melhoria precisam se concentrar.

Tabela 7 Resultado compilado da avaliação das revistas multimídia

\begin{tabular}{|c|c|c|c|c|c|c|c|c|c|}
\hline \multicolumn{2}{|c|}{ Subsistema de interação } & \multicolumn{4}{|c|}{ Pais \& Filhos } & \multicolumn{4}{|c|}{ Embalagem Marca } \\
\hline Interface & Segmento & A & $\mathbf{P}$ & $\mathbf{N}$ & $\mathrm{N} / \mathrm{A}$ & A & $\mathbf{P}$ & $\mathbf{N}$ & N/A \\
\hline Aplicativo & Barra navegação & 4 & 1 & 1 & 0 & 4 & 1 & 1 & 0 \\
\hline \multirow[t]{3}{*}{ Revista } & Geral & 4 & 2 & 0 & 0 & 4 & 1 & 1 & 0 \\
\hline & Matéria & 2 & 2 & 0 & 0 & 3 & 0 & 0 & 1 \\
\hline & Subtotal & 10 & 5 & 1 & 0 & 11 & 2 & 2 & 1 \\
\hline \multicolumn{10}{|c|}{ Subsistema de navegação } \\
\hline Interface & Agrupamento & A & $\mathbf{P}$ & $\mathbf{N}$ & $\mathbf{N} / \mathbf{A}$ & A & $\mathbf{P}$ & $\mathbf{N}$ & N/A \\
\hline Aplicativo & Barra navegação & 4 & 1 & 1 & 0 & 4 & 0 & 1 & 1 \\
\hline \multirow[t]{5}{*}{ Revista } & Geral & 3 & 1 & 1 & 2 & 4 & 1 & 2 & 1 \\
\hline & Capa/sumário & 2 & 1 & 0 & 0 & 0 & 3 & 0 & 0 \\
\hline & Matérias & 3 & 0 & 1 & 2 & 1 & 1 & 1 & 3 \\
\hline & Subtotal & 11 & 3 & 4 & 4 & 9 & 5 & 4 & 4 \\
\hline & Total & 21 & 8 & 5 & 4 & 20 & 7 & 6 & 5 \\
\hline
\end{tabular}

\section{Conclusões e desdobramentos}

Através das recomendações presentes na literatura, complementada com a observação direta do objeto de estudo, obteve-se um modelo descritivo-normativo passível de ser utilizado no design de revistas multimídia, em sua fase de análise de similares, bem como para avaliação e redesign de revistas já existentes . Este modelo descritivonormativo atendeu ao objetivo inicial do presente estudo ao caracterizar e avaliar as revistas multimídia selecionadas, conforme demonstrado no item 4 .

Porém, como o modelo descritivo-normativo foi utilizado apenas pelos autores na caracterização/avaliação de duas revistas multimídia, será necessário um processo de validação e aprimoramento deste modelo a partir de testes com equipes de design de revistas multimídia.

Vislumbra-se como outros desdobramentos a continuidade do estudo para a adaptação e aplicação do modelo em outros tipos de publicações digitais, e também como instrumento de pesquisa em estudo analítico com revistas multimídia a ser realizado futuramente. 


\section{Agradecimento}

À agência de fomento CAPES pelo apoio a esta investigação, por meio da concessão de bolsa para nível de mestrado, sem a qual este estudo não seria possível.

\section{Referências}

AGNER, L. Em busca de um olhar interdisciplinar sobre a arquitetura de informação, a usabilidade e a metacomunicação em dispositivos móveis com interfaces gestuais. In: V SIMPÓsıo NACIONAL ABCiber, 5, 2011, Florianópolis. Anais... Florianópolis: ABCiber, 2011.

AGNER, L. Jornalismo para tablets: interações gestuais em um aplicativo de notícias. In: CONGRESSO BRASILEIRO DE PESQUISA E DESENVOLVIMENTO EM DESIGN, 10, 2012, São Luís. Anais... São Luís: Universidade Federal do Maranhão. 2012.

AGNER, L. Jornalismo digital nos tablets e interação gestual. In: BARBOSA, A. C. L. S., RANGEL, M. M.; RAPOSO, M. (org). Ergonomia design usabilidade interação. Juiz de fora: MAMM/UFJF. 2013.

APPLE Inc. iOS human interface guidelines. Cupertino: Apple Inc. 2012. BÉHAR, P.; COlOMbAnI, L. \& KRISHnan, s. Publishing in the digital era: a Bain \& Company study for the Forum D'Avignon. Paris: Bain \& Company, Inc. 2011. Disponível em: <http://www.bain.com/Images/BB_Publishing_in_the_ digital_era_4_11.pdf $>$. Acesso em: 30 Abr 2012.

BUDIU, R. \& NIELSEN, J. Usability of iPad apps and websites. 2nd edition. Fremont: Nielsen Norman Group. 2011. Disponível em: <http://www.nngroup.com/ reports/mobile/ipad/ipad-usability_2nd-edition.pdf>. Acesso em 20 Abr. 2012.

CUNHA, R. E. S. \& ARAGÃo, R. M. Clicar, arrastar, girar: o conceito de interatividade em revistas para iPad. ENCONTRO NACIONAL DE PESQUISADORES EM Jornalismo, 9, 2011. Anais... Rio de Janeiro: Associação Brasileira de Pesquisadores em Jornalismo. 2011.

HEIKKILÄ, H. Cross roads of tablet publishing: recommendation for dynamic cross media workflows. Espoo: Next Media. 2012. Relatório de pesquisa.

KuHnA, M. Content modeling for publishing purposes. Espoo: Next Media. 2012. Relatório de pesquisa.

LOHMAN, A.; ROCHA, L. \& BITARELlo, B. A influência da evolução tecnológica sobre a narrativa da notícia: estudo de caso da Wired Magazine. In: CONFERÊNCIA LATINo AMERICANA DE DeSign DE INTERAÇÃo, 9, 2011. Anais... Belo Horizonte: IxDA-Belo Horizonte. 2011. 


\section{Sobre os autores}

Sergio R. Gurski

<sergiogurski@hotmail.com>

Mestrando, UFPR, Brasil

\section{Stephania Padovani}

<s_padovani2@yahoo.co.uk> PhD, UFPR, Brasil

\section{Maicon B. Puppi}

$<$ maicon.puppi@gmail.com>

Mestrando, UFPR, Brasil 